\title{
Ecological Discourse Analysis
}

\author{
Yina $\mathrm{Wu}$ \\ Xiamen University Tan Kah Kee College \\ Zhangzhou, Fujian, China \\ Email:sandywyn@xujc.com
}

\begin{abstract}
Ecology has inevitably become the core issue of the 21st century, and ecolinguistics, the interdiscipline of ecology and linguistics, therefore has become the focus of study. This paper starts with different definitions of ecolinguistics, then contras ts "ecological discourse analysis" with "the analysis of ecological discourse" and "language ecology", and comes to the conclusion that ecolinguistics is much more than the study of language ecology or the analysis of texts that happen to be about environmental or ecological issues. Rather, ecolinguis tics should include the analysis of all discourses within an ecological frame work which considers the impact of the discourses on the systems which support life. In other words, ecolinguis tics should be the ecological analysis of all discourses. Perhaps the ideal future for ecolinguistics is for different new studies to emerge that are based on explicit ecosophies and are practically useful in resisting the discourses that underlie an ecologically destructive and socially unjust society.
\end{abstract}

Keyword-ecolinguistics, ecological discourse analysis, language ecology, ecosophies

\section{DEFINITION OF ECOLINGUISTICS}

Ecolinguistics is obviously the combination of ecology and linguistics, two disciplines which appear to be unconnected at first. Stibbe (2014) points out the disconnection occurs only if ecology - the study of the relationship of organisms with each other and the physical environment - fails to include human beings as organisms[1]. An inclusive view would be that ecology consists of the relationships of humans with other humans, other organisms, and the physical environment. Language, then, is relevant to the extent that it plays a part in how humans link to each other, to other organisms and to the environment. Language can, to certain extent, influence the way we think about the world, which in turn affects how we act, hence language can inspire us to protect or destroy the ecosystems that life depends on. In this sense, ecolinguistics is about critiquing forms of language that encourage ecologically destructive behavior or lead to ecological destruction and helping to look for those which encourage relationships of care and respect for the natural world or inspire people to protect the environment. But ecolinguistics is much more than this. The term 'ecolinguistics' has been used since the 1990s [2], and the word 'ecology' has been included in linguistic study since at least Einar Haugen, who was the first one to come up with the definition of language ecology in 1972: Language ecology is defined as the study of interactions between any given language and its environment. According to Haugen, the true environment of a language is the society that uses it as one of its codes. Language exists only in the minds of its users, and it only functions in relating these users to one another and to nature, or, in other words, their social and natural environment. Part of its ecology is therefore psychological: its interaction with other languages in the minds of bi- and multilingual speakers. Another part of its ecology is sociological: its interaction with the society in which it functions as a medium of communication. The ecology of a language is determined primarily by the people who learn it, use it, and transmit it to others [3]. The term 'ecolinguistics' has been applied to a number of different approaches and interests, for example, ecolinguistics has been used to describe studies of the blend of languages in multicultural schools; studies of language diversity and interaction; studies of some languages or dialects that are going extinct in certain areas; studies of discourses such as outdoor signposts; and analysis of texts that happen to be about the environment or are related to the environment such as animals, natural resources, economics, advertising, energy, ecotourism or climate change. Stibbe points out the diversity of approaches stems from different understanding of the concept of 'ecology', from a broad concept of 'the interaction of some things with other things' to narrow concepts such as 'related to environmentalism'[4]. Kravchenko argues that because there has been continuing debate in academic language study about what its epistemological foundations should be, there isn't a unified discipline called "linguistics", but a range of linguistic subfields such as sociolinguistics, psycholinguistics, neurolinguistics, anthropolinguistics, ethnolinguistics, and cognitive linguistics. These disciplines focus on specific aspects of language that are considered important in understanding its nature and function, but they do not essentially vary in viewing language as a kind of tool, the use of which is specified or affected by a certain factor highlighted in the name of the discipline[5]. But Stibbe maintains that 'linguistics' of ecolinguistics is simply 'the use of techniques of linguistic analysis to reveal the stories-we-live-by, opening them up to question and challenge from an ecological perspective [4].

Cowley observes there is not enough discussion of biology or even of biological terms in ecolinguistics. And most researchers acknowledge that "language ecology" is used to refer either to circumstantially determined language use, where language is viewed as a tool, or to the circumstantially determined behavior of language viewed as a living organism; both views are themselves built on metaphors - the instrumental metaphor and the biomorphic metaphor, respectively. Language is a outstanding feature of the human species, but it does not exist as a thing out there, much less as an organism; however, "ecolinguists tend to separate nature from participating in language"[6]. Stibbe points out that ecolinguistics, in essence, consists of questioning the stories 
that support our current unsustainable civilization, exposing those stories that are clearly not working, that are leading to ecological destruction and social injustice, and finding new stories that work better in the conditions of the world that we face[1]. Alexander and Stibbe(2014) point out if we define linguistics simply as 'the study of language", we end up with defining ecolinguistics as "the study of the impact of language on the life-sustaining relationships among humans, other organisms and the physical environment. It is normatively orientated towards preserving relationships which sustain life."[7] In other words, ecolinguistics is concerned with how language participate in forming, maintaining, influencing or destroying relationships between humans, other life forms and the environment. The word 'humans' is used rather vaguelywhat is meant is neither humans all together, since it would be unlikely to generalize, nor specific individuals, since on their own few people would have a big impact on general human behavior. Instead, the most appropriate understanding appears to be groups of humans as they are organized into professions, industries, cultures, and societies. Groups of humans coordinate their practices and world-views using discourses particular ways of talking about, writing about, representing, and, ultimately, constructing reality. Discourses with clusters of linguistic features used by groups when they talk about the world, which come together to produce specific models of reality. These models or shaping devices enable humans to construct relationships with the real world and so a primary concern of ecolinguistics is these models, and the cluster of linguistic features which make them.

Dissatisfied that ecolinguistics currently remains a theory without unified conceptual foundations, Steffensen and Fill redefine ecolinguistics as: (1) the study of the processes and activities through which human beings - at individual, group, population and species levels- exploit their environment in order to create an extended, sense-saturated ecology that supports their existential trajectories, as well as (2) the study of the organismic, societal and ecosystemic limits of such processes and activities, i.e. the carrying capacities for upholding a sound and healthy existence for both human and non-human life on all levels.[8] They begin by identifying the four different ways in which the ecology of language has been conceptualized. They are: a symbolic ecology (the idea of the environment of a language as other languages), a natural ecology (the idea of language as dependent on the natural habitat of language users), a sociocultural ecology (the idea of how sociocultural factors impact on language in various contexts), and a cognitive ecology (based in Gibson's ecological psychology and the environmental affordances for the organism's action-perception cycles). The conceptual diversity results from the different views on language ecology: "If one adopts the metaphor that SCIENTIFIC DISCIPLINES ARE TERRITORIES, ecolinguistics appears more like an archipelago than a continent”. Such disparity is not so much a consequence of whether the notion of language ecology is used metaphorically or non-metaphorically, which was proposed by Fill in an earlier study.[2]

\section{LANGUAGE ECOLOGY}

Haugen (1972) was the first one to come up with the definition of language ecology. He uses the term 'ecology' metaphorically, and concerns the relationships of languages to other languages and the places where the languages are spoken. Within this metaphor, languages are treated as species, interacting with each other and displacing each other, and they are viewed as likely to become endangered or extinct, which aims to protect and enhance the status of minority or endangered languages. This is in contrast with ecolinguistics, as defined by Steffensen and Fill(2014), where ecology is taken literally as the life-sustaining relationships between humans, other organisms and the physical environment. However, the two approaches are not entirely different.

Fill and Penz (2007) use 'Sustaining Language' as the title of a collection of essays in applied ecolinguistics[9]. The ambivalent wordplay contains the two approaches. On the one hand there is the task of preserving linguistic diversity, and on the other hand there is language which encourages people to act in ways which preserve the physical ecosystems that support life, 'language which sustains life'. This recalls a distinction made by Halliday (2007: 14) between 'institutional ecolinguistics, the relation between a language and those who speak it (and also, in this case, those who may be speaking it no longer)', and 'what we might call systemic ecolinguistics', which concerns the impact of language on human decision making and consequently on the ecologically significant actions that humans take [10]. Fill and Penz's (2007) collect essays both about the influence of specific forms of language on ecosystems and 'language ecology', which emphasizes the preservation of linguistic diversity[9]. But the goals of the two groups of essays are not unrelated. The essays on 'language ecology' maintain that there is a relationship between linguistic diversity and biological diversity. Diversity is therefore the bracket linking Halliday's two dimensions. On the consequences of languages dying out, Halliday says 'it is tempting to argue from the biological to the linguistic sphere, and to say, just as diversity of species is necessary to environmental, ecological well-being, so diversity of languages is necessary to cultural, ecosocial well-being. But does the analogy hold?' [10] This is considered to remain a moot point.

Muhlhausler(2003) thinks language is interconnected with the world-it both constructs and is constructed by it. Language is interlinked with the world in 'numerous complex ways'[11]. He takes the ecological view that many interrelationships and inter-dependencies in any ecology are mutually beneficial and that some are exploitative and parasitical. In a healthy balanced ecology about $90 \%$ of the interrelationships are mutually beneficial. He proposes another ecological hypothesis that diversity is needed for the long-term sustainability of any ecology. He argues against the growthism of the English language, which can be seen as parallel to Halliday's (1990) arguments against economic growthism[12]. Muhlhausler argues when local languages are displaced by dominant world languages such as English what is lost are the discourses which encode everything people have learned about living sustainably in the local environment. These are replaced by discourses such as those of consumerism, economic growth and neoliberalism that are at the core of an unsustainable society. The prospect of English moving from a foreign language to a second language to the sole language of a growing number of communities is clearly, then, ideological. 
In the social world, use of the dominant neo-liberal discourse that holds that the spread of English is a 'natural' process needs questioning. But Pennycook (1999) holds a different view: 'Taken alone, however, the language ecology metaphor is limited since it relies so heavily on a notion of what is 'natural' and therefore on what may at times appear a conservative notion of preservation ... conservation may easily slide into conservatism.' [13] The main criticism of the 'language ecology' metaphor, however, is that while the general mapping of endangered species to endangered languages appears logical enough, there is no reason to expect languages to interact with each other and the physical environment in ways which parallel the way that organisms do, since the languages are not subject to the same laws of thermodynamics, energy flows and geochemical cycles as species are.

In short, 'language ecology' is a metaphor with both pros and cons. The danger of the metaphor is that any kind of research which happens to consider the relationships between languages and the places where they are spoken is labeled 'ecolinguistics' because of the metaphor rather than any relationship to actual ecology. Only when research explores the implications of language contact or linguistic diversity for human behavior and the consequent impact on real, physical ecosystems does it become 'ecolinguistics'. Alexander and Stibbe(2014) believe it would be quite possible to explore the implications of language contact on the ecosystems which support life without using the word 'ecology' to refer to the interaction of languages with each other. It would be possible to explore, for example, how local sustainable discourses are displaced by dominant global discourses of consumerism and neoliberalism through the global spread of English without using the term 'language ecology'[7].

\section{ANALYSIS OF ECOLOGICAL DISCOURSE}

Over the past three decades, a lot of researches have been carried out to analyze the discourse on a wide range of ecological issues and activities. Numerous methods have been applied to show how aspects of the ecology and environment have been articulated and construed in the media and advertizing fields. This paper will review some representative findings to illustrate the major themes and approaches involved.

Gerbig (1993) and Schleppegrell (1996) focus on features rendering abstraction and agency or lack of it. Nominalization is a feature which allows the agent to be omitted, for example, 'extinctions of the rainforest' omits the agent, leaving unstated who is responsible for the extinction[14][15]. Other studies focus on lexical choices and their implications. For example, Goatly (2000) points out that when we use the word environment, we presume that humans are central and more important than nature[16]. Fill and Muhlhausler (2001) are considered to have made contributions to the now established field of ecolinguistics with many articles explicitly analyzing ecological discourse. Such research brings out the involvement of the language system in constructing or shaping a viewpoint on ecological issues. Goatly (2002) adopts critical discourse analysis (CDA) to investigate the representation of nature on the BBC World Service radio. He believes that human connections and news values feed into the way nature is 'constructed' by the BBC, while there are alternative ways to represent nature.[17] Alexander (2009) combines CDA with corpus linguistic techniques. A corpus renders quantitative data, which can underpin results from a CDA approach, thus showing empirically how specific linguistic features serve to uphold discourse processes. For example, he interrogates how oil companies and agribusiness utilize language to argue for and propagate selected positions in relation to the current ecological crisis. The book sets out to unpick lexical and discourse patterning and unearths some disturbing truths along the way[18].

\section{ECOLOGICAL ANALYSIS OF DISCOURSE}

Ecolinguistics should focus on analyzing discourses which have an impact on the way humans interact with each other, other species and the environment. The themes of the discourses analyzed include environmentalism, ecology, and biological conservation, but these are not the only discourses that have an impact on how humans treat the systems that support life. In fact, texts such as animal industry handbooks, lifestyle magazines, and economics textbooks have a potential impact on human behavior even though they are not part of explicitly 'environmental' or 'ecological' discourses.

Halliday (1990) starts off the discipline of ecolinguistics by investigating aspects of grammar which he claims 'conspire to construe reality in a certain way ... that is no longer good for our health as a species' instead of by analyzing the language of the environmental movement. The first point he mentions is that mass nouns like soil and water are unbounded and do not therefore reflect the limited supply of such essential resources; the second is that antonymic pairs have a positive (unmarked) pole which means that 'bigger' is associated with 'better'; the third is that humans tend to be agent in grammar more frequently than other species; the fourth is that pronoun use and mental processes divide the world falsely into conscious beings (humans and to some extent their pets) and non-conscious beings (other species). But Halliday is not optimistic about the power of ecolinguistics to address sustainability issues, mainly because his analyses focus on the level of the general grammar of languages. He writes 'I do not think even the language professionals of AILA can plan the inner layers of grammar' [19]. For example, the word 'growth' is intrinsically positive, therefore, the idea that the economy must shrink, or that 'economic shrinkage is good' is unlikely to be accepted. Obviously, in this sense, ecolinguists cannot intervene on the level of grammar. But Alexander R.\& Stibbe(2014) suggest a more realistic approach would be to accept that the term 'growth' is part of an economic discourse that models or shapes reality in a certain way, and search for whole alternative models or discourses with greater practical adequacy. Instead of trying to change the grammar of the English language by altering the marking of the term 'growth', it is more ideal just to stop talking about growth, because it is not a measure of anything important, and start talking about something like wellbeing instead[7]. They draw two conclusions from this. One is that what is a more promising level for ecolinguistics to concentrate on is the clustering of grammatical and semantic features within certain discourses than general comments about the 'grammar of English'. The second is that the analysis of the potential impact of particular 
discourses on human behavior and hence on the ecosystems that support life is most important for ecolinguistics[7]. In other words, ecolinguists should analyze any discourses within an ecological framework, rather than simply analyze discourses which happen to be about the environment. Ecological framework consists of a set of philosophical background assumptions which form a structure grounding the normative orientation. The assumptions are about values, such as whether life is valuable, or whether both human life and the life of other animals and plants are valuable. The assumptions are also about the conditions allowing valued outcomes to occur, such as the role of biodiversity and the climate system in supporting life and allowing beings to flourish according to their nature.

Stibbe(2014) mentions that ecolinguistic studies are based on a number of different philosophical or ethical frameworks, both on ecological dimensions and social ones[1]. He points out Naess's (1996) term 'ecosophy' is useful for describing frameworks that ecolinguistic studies use to judge discourses against: "By an ecosophy I mean a philosophy of ecological harmony ... openly normative it contains norms, rules, postulates, value priority announcements and hypotheses concerning the state of affairs ... The details of an ecosophy will show many variations due to significant differences concerning not only the 'facts' of pollution, resources, population, etc. but also value priorities."[20] Ecosophies range along a series of spectra from anthropocentric to ecocentric, optimistic to pessimistic, and neoliberal to socialist, localist or anarchist. It is for the ecolinguist to survey the wide range of philosophies that are 'out there' in the literature critically, consider them carefully in light of available evidence and their own experience of human communities and the natural world, and then build their own ecosophy through combining them, extending them or creating something entirely new. The ecosophy has to be scientifically possible, plausible, and aligned with the available evidence[1]. In sum, what ecolinguistics potentially has to offer critical discourse studies is (a) an expanded range of issues of importance for discourse analysts to address, (b) a more com-prehensive and explicit philosophical framework for judging discourses against - one which does not gloss over ecological aspects, and (c) theoretical insights into 'how discourse works' derived from examining new data from a new approach. It is, however, an emerging area, with few studies of depth and sophistication. Perhaps the ideal future for ecolinguistics is for numerous new studies to emerge that are based on explicit and well-thought-out ecosophies and are practically useful in resisting the discourses that underlie an ecologically destructive and socially unjust society.

\section{CONCLUSION}

One of the challenges ecolinguistics can address is consumer culture that is deeply embedded in numberous discourses, from advertising to news reports, through exposing the ecologically destructive ways that everyday discourses construct notions of the 'good life', providing tools to help resist those discourses, and searching for beneficial discourses which actively identify the 'good life' with something other than consumerism. But ecolinguistics is much more than the study of language ecology or the analysis of texts that happen to be about environmental or ecological issues. Rather, ecolinguistics should include the analysis of all discourses within an ecological framework which considers the impact of the discourses on the systems which support life. In other words, ecolinguistics should be the ecological analysis of all discourses. Perhaps the ideal future for ecolinguistics is for different new studies to emerge that are based on explicit ecosophies and are practically useful in resisting the discourses that underlie an ecologically destructive and socially unjust society.

\section{REFERENCES}

[1] Stibbe. A. AN ECOLINGUISTIC APPROACH TO CRITICAL DISCOURSE STUDIES. Critical Discourse Studies. 2014, 117-128.

[2] Fill, A., \& Muhlhausler, P., The Ecolinguistics Reader. Language, Ecology and Environment. London, Continuum. 2001.

[3] Haugen, E., The Ecology of Language. Stanford University Press. 1972.

[4] Stibbe, A. Ecolinguistics: Language, Ecology and the Stories We Live By London: Routledge. 2015.

[5] Kravchenko. A.V. Two views on language ecology and ecolinguistics. Language Sciences 2016: 102-113.

[6] Cowley, S.J., Bio-ecology and language: a necessary unity. Language Sciences 2014: 60-70.

[7] Alexander R.\& Stibbe A. From the analysis of ecological discourse to the ecological analysis of discourse. Language Sciences2014: 104-110

[8] Steffensen S \& Fill A. Ecolinguistics: the state of the art and future horizons. Language Sciences 2014:6-25.

[9] Fill, A., \& Penz, H., Sustaining Language. Essays in Applied Ecolinguistics. LIT Verlag, Vienna. 2007.

[10] Halliday, M.A.K., Applied linguistics as an evolving theme. In: Webster, J. (Ed.), Language and Education: Collected Works of M.A.K. Halliday. Continuum, London. 2007.

[11] Muhlhausler, P., English as an exotic language. In: Mair, C. (Ed.), The Politics of English as a World Language. New Horizons in Postcolonial Cultural Studies. Rodopi, Amsterdam, New York. 2003.

[12] Alexander, R.J., Global languages oppress but are liberating, too: the Dialectics of English. In: Mair, C. (Ed.), The Politics of English as a World Language. New Horizons in Postcolonial Cultural Studies. Rodopi, Amsterdam, New York. 2003.

[13] Pennycook, A., Development culture and language: ethical concerns in a postcolonial world. The Fourth International Conference on Language and Development. 1999.

[14] Gerbig, A., The representation of agency and control in texts on the environment. In: A lexander, R.J., Bang, J.C., D00r, J. (Eds.), Papers for the symposium 'Ecolinguistics. Problems, theories and methods' AILA 1993. Odense University, Odense. 1993.

[15] Schleppegrell, M.J., Abstraction and agency in middle school environmental education. In: Bang, J.C., Door, J., Alexander, R.J., Fill, A., Verhagen, F. (Eds.), Language and Ecology: Eco-Linguistics. Problems, Theories and Methods. Essays for the AILA 1996 Symposium. Odense University, Odense. 1996.

[16] Goatly, A., Critical Reading and Writing. Routledge, London and New York. 2000.

[17] Goatly, A., The representation of nature on the BBC world service. Text. 2002.

[18] Alexander, R.J., Framing Discourse on the Environment. A Critical Discourse Approach. Routledge, New York and London. De Beaugrande, R., 2006. Critical discourse analysis: history, ideology, methodology. Studies in Language \& Capitalism. 2009.

[19] Halliday, M.A.K., 1990. New ways of meaning. A challenge to applied linguistics. Journal of Applied Linguistics 1990. (6), 7-36.

[20] Naess, A. The shallow and the long range, deep ecology movement. In A. Drengson \& Y. Inoue (Eds.), The deep ecology movement: An introductory anthology (pp. 3-10). Berkeley, CA: North Atlantic Books. 1996. 